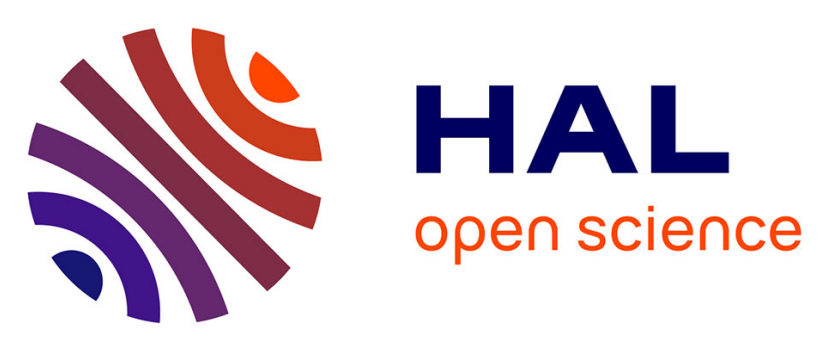

\title{
Numerical simulation of thermoconvective flows and more uniform depositions in a cold wall rectangular APCVD reactor
}

\author{
Xavier Nicolas, Abderrahmane Benzaoui, Shihe Xin
}

\section{To cite this version:}

Xavier Nicolas, Abderrahmane Benzaoui, Shihe Xin. Numerical simulation of thermoconvective flows and more uniform depositions in a cold wall rectangular APCVD reactor. Journal of Crystal Growth, 2008, 310 (1), pp.174-186. hal-00692097

\section{HAL Id: hal-00692097 https://hal.science/hal-00692097}

Submitted on 27 Apr 2012

HAL is a multi-disciplinary open access archive for the deposit and dissemination of scientific research documents, whether they are published or not. The documents may come from teaching and research institutions in France or abroad, or from public or private research centers.
L'archive ouverte pluridisciplinaire HAL, est destinée au dépôt et à la diffusion de documents scientifiques de niveau recherche, publiés ou non, émanant des établissements d'enseignement et de recherche français ou étrangers, des laboratoires publics ou privés. 


\title{
Numerical simulation of thermoconvective flows and more uniform depositions in a cold wall rectangular APCVD reactor.
}

\author{
Xavier NICOLAS ${ }^{1}$, Abderrahmane BENZAOUI ${ }^{1}$, Shihe XIN ${ }^{2}$ \\ ${ }^{1}$ Université Paris-Est, LETEM, EA2546, \\ 5 Bd Descartes, 77454 Marne la Vallée Cedex 2, France \\ ${ }^{2}$ CETHIL, UMR 5008 CNRS/Insa-Lyon, \\ 9, Rue de la Physique, 69621 Villeurbanne Cedex, France
}

\section{Corresponding author: Xavier NICOLAS}

Postal address: Université Paris-Est, Bât. Lavoisier, LETEM, 5 Bd Descartes, 77454 Marne la Vallée Cedex 2, France.

Tel: [33] 160957314

Fax: [33] 160957294

E-mail: nicolas@univ-mlv.fr

Other author e-mail: benzaoui@univ-mlv.fr, shihe.xin@insa-lyon.fr

\begin{abstract}
At atmospheric pressure, the usual flow conditions in the cold wall horizontal rectangular thermal CVD reactors correspond to steady longitudinal thermoconvective rolls that make non uniform vapor depositions, in shape of longitudinal parallel ridges. In order to get more uniform depositions, the pressure is generally lowered under the atmospheric pressure to promote forced convection flows, instead of mixed convection ones. In the present paper, using three-dimensional direct numerical simulations, we propose and analyse a method to get uniform deposition without lowering the pressure in the reactor. It consists in adequately exciting the parallel thermoconvective rolls at channel inlet to make them unsteady, periodic and sinuous in order to get a uniform time average of the deposition. This method is shown to be adapted for the horizontal and rectangular APCVD reactors with large longitudinal and
\end{abstract}


transversal aspect ratios, when the Reynolds number of the gas flow is $O(100)$, whatever the value of the surface Damköhler number. This situation is encountered in the online or scrolling APCVD reactors used to deposit coatings on float glass in the flat glass industry for instance. The simulations are based on simplified models for the transport equations (Boussinesq model) and the kinetics of the heterogeneous reactions (deposition model of silicon from hydrogen and silane: $\mathrm{SiH}_{4} \rightarrow \mathrm{Si}+2 \mathrm{H}_{2}$ ).

Keywords: A1. Computer simulation, Surface deposition structure, Thermoconvection, Rectangular thermal CVD reactor, A3. Atmospheric pressure chemical vapor deposition, Metalorganic chemical vapor deposition

PACS codes: 47.27.Te Convection and heat transfer, 81.15.Gh Chemical vapor deposition

\section{Introduction}

This paper presents numerical simulations of the flow and transport phenomena in a horizontal rectangular thermal CVD reactor. This type of reactor was probably the most used for high volume production of silicon epitaxial wafers till the 1970s and is probably the most widely investigated configuration. It still remains an important configuration for research, for low-pressure and low temperature metal-organic CVD (MOCVD) (see Ern et al. [1, 2]), for Ti-Si CVD (see Pons et al. [3]) and for the on-line Atmospheric Pressure CVD (APCVD) of coatings on float glass in the glass industry (see Gordon [4], Sheel and Pemble [5]). As reviewed by Kleijn [6] and Mahajan [7], the two most studied chemical systems in this reactor type have been those conducting to the silicon growth from silane and to the GaAs growth from trimethylgallium and arsine. More recently, this reactor has also been used to deposit epitaxial layers of silicon carbide at atmospheric pressure and at high temperature (see Kuczmarski [8], Meziere et al. [9], Nishizawa and Pons [10]). 
In all cases, the working principle of this reactor type is the following: a gaseous mixture made of a neutral gas (hydrogen or less often nitrogen) and of one or several diluted reactive gases (silane, trimethylgallium and arsine, organo-metallic tin compounds ...) is injected in the reactor. The gaseous mixture flows over a heated substrate placed on the bottom plate of the reactor. Under pyrolysis effects, chemical reactions occur in the gaseous mixture and on the substrate surface on which the desired material deposits. However, depending on the gas nature and on the deposition type, the working conditions vary. The rectangular chamber of the horizontal thermal reactors can have "cold walls" (near the ambient temperature: $T_{c} \sim 300$ $\mathrm{K}$ ) or "hot walls". The substrate temperature $\mathrm{T}_{\mathrm{h}}$ varies between 700 and $950 \mathrm{~K}$ for the on-line APCVD in the glass industry $[4,5,11]$, between 800 and $1100 \mathrm{~K}$ for MOCVD [1, 2, 12], between 1050 and $1400 \mathrm{~K}$ for silicon epitaxy [7, 12] and up to $1900 \mathrm{~K}$ for silicon carbide CVD [8-10]. The Prandtl number is $\operatorname{Pr} \approx 0.7$. The Reynolds number Re is generally smaller than 100, except in some online or scrolling CVD processes like in the APCVD reactors used on float-glass in the flat glass industry. In this case, Re is O(100) or higher because the average velocity of the gas mixture must be higher than the scrolling velocity of the glass ribbon (see below). The channel height $\mathrm{H}$ varies between 1 to $10 \mathrm{~cm}$ and the substrate is generally tilted by a small angle of 2 to $10^{\circ}$ to the horizontal to permit a more uniform vapor deposition in the axial direction (see Mahajan [7], Park and Pak [13]). As a consequence, the Rayleigh number Ra can vary between small values $(<1500)$ at the lowest values of $H$ and of the pressure $\left(\sim 10^{3} \mathrm{~Pa}\right.$ for MOCVD) and can reach $\mathrm{Ra}=80000$ (for hydrogen) and $\mathrm{Ra}=3.5 \times 10^{6}$ (for air and nitrogen) at the atmospheric pressure, for the highest $\mathrm{H}$ values $(\mathrm{H}=10 \mathrm{~cm})$ and the smallest average temperature $\left(\left(T_{c}+T_{h}\right) / 2=500 \mathrm{~K}\right)$. Therefore, when $\mathrm{Ra}<1500$, the flow regime is a forced convection flow, with sometimes a steady transversal roll at the leading edge of the heated plate as shown by Visser et al. [14] and Ingle and Mountziaris [15]. The flow regime is a laminar mixed convection flow that can be steady or unsteady, periodic or non-periodic, when $2000<\mathrm{Ra}<\mathrm{O}\left(10^{5}\right)$, and that becomes chaotic and even turbulent when $\mathrm{Ra} \sim O\left(10^{6}\right)$ [16-19]. 
Consequently, the horizontal rectangular reactors, with cold walls, a horizontal heated substrate and a pressure close to the atmospheric pressure exactly correspond to the Poiseuille-Rayleigh-Bénard (PRB) configuration, that is to say mixed convection flows in horizontal rectangular channels heated from below. Furthermore, for the above parameters (for $\operatorname{Pr} \approx 0.7, \operatorname{Re}=O(100)$ and $\operatorname{Ra}>2000$ ), it is well known that the PRB flow patterns are steady longitudinal thermoconvective rolls (see Kelly [20] and Nicolas [21] for exhaustive and recent reviews on PRB flows and on their stability). As a consequence, such a thermoconvective flow in a CVD reactor of this type makes transversally non uniform vapor depositions, in shape of longitudinal and parallel ridges (see Moffat and Jensen [22, 23] and Kleijn and Hoogendoorn [24]). That is why the pressure is generally lowered under the atmospheric pressure in CVD reactors: the density of the gaseous mixture decreases, which promotes forced convection flows and more uniform deposits (since the Rayleigh number is proportional to the square of density). However, this increases the cost of the CVD reactors and of the produced materials. Furthermore, lowering the pressure is sometimes impossible, as is the case of the APCVD reactors on the production lines of float glass for instance.

Thus, several solutions have been proposed in literature to obtain transversally more uniform depositions in rectangular CVD reactors without lowering the pressure. Evans and Greif [25, $26]$ propose to deposit the coatings at very small Reynolds numbers $(\operatorname{Re}<10)$ and moderate Rayleigh numbers $\left(\mathrm{Ra}<10^{4}\right)$ so as to make transversal thermoconvective rolls to appear in the reactor. Indeed, the displacement of these laminar rolls in the mean flow direction permits to get transversally more uniform layers than with the longitudinal rolls. However, the transversal rolls are a stable flow pattern only in narrow channels at low Re values (say for Re $<10$ and a transversal aspect ratio $B=l / H<10$, at $P r \approx 0.7$ [27]). Evans and Greif [16], Hosokawa et al. [17] and Spall [18] propose to use the unsteady flows (periodic or chaotic) that exist at low $\operatorname{Re}(\operatorname{Re}<100)$ and large $\operatorname{Ra}\left(10^{5}<R a<O\left(10^{6}\right)\right)$ when $\operatorname{Pr} \approx 0$, 7. Indeed, in this 
case, the time average of the heat transfer and of the deposition rate on the substrate becomes more uniform in the transversal direction of the reactor. As shown by the linear stability analysis of Clever and Busse [28] (for $B \rightarrow \infty$ ) and Kato and Fujimura [29] (for B=1), these unsteady flows result from the oscillating, varicose or skewed varicose instabilities of the longitudinal rolls that appear approximately for $R e<70$ and $R a>5000$. However, these theories are based on the Boussinesq approximation and consider constant physical properties. When the relative temperature difference $\varepsilon=\left(T_{h}-T_{c}\right) / T_{c}$ is large (as is in APCVD and MOCVD, since $\varepsilon \approx 2$ ), the physical properties vary with temperature and these unsteady flows seem to appear for Re $<70$ but at higher Rayleigh numbers (at $R a>O\left(10^{5}\right)$ in references [16, 18] for instance). Following the same idea as above, to destabilize or control the longitudinal roll flows more easily and to get more uniform deposition, Spall [18] perturbs the flow and makes it unsteady by rotating the channel 2 degrees about the longitudinal axis over a time span of 1 second and Koizumi and Hosokawa [30] use non uniform thermal boundary conditions on the vertical lateral walls. In the case of vertical cylindrical CVD reactors, using Large Eddy Simulations, Van Santen et al. [31] also propose to use the effect of turbulence in the gaseous mixture, resulting from buoyancy at high operating pressure. They show that, with turbulent flows, the deposition rate is higher and more uniform in a large part of the heated susceptor.

In most of the CVD studies in rectangular reactors cited above, the considered rectangular reactors concern the electronic and semi-conductor industry. They have small transversal and longitudinal aspect ratios: $B=l / H=2$ in general or is leather than 4 and $A=L / H<20$. In this case, the thermoconvective roll unsteadiness appears more easily than when B is large (for $B>10$ for instance) because, at small $B$, there is a competition between the transversal rolls (that are promoted by the lateral confinement) and the longitudinal rolls (that are promoted by the mean flow) $[20,21,27]$. In the extreme case, when $B \rightarrow \infty$, the transversal rolls cannot appear since the longitudinal rolls are always more unstable than the transversal rolls. 
The aim of the present paper is to propose a solution to obtain transversally more uniform depositions in rectangular APCVD reactors, without lowering the pressure, when the transversal and longitudinal aspect ratios are large $(A>30$ and $B>10)$, for $\operatorname{Re}>70$ $(\operatorname{Re} \sim O(100))$ and for $3000<R a<O\left(10^{5}\right)$. This reactor configuration corresponds, for instance, to the online or scrolling APCVD reactors used to make coatings on the flat glass produced by the "float" process (titanium dioxide coatings for self-cleaning glasses, fluorine-doped tin oxide coatings for low emissivity glasses, ...). In this process, the APCVD reactor is located at the outlet of the tin bath, where the glass temperature is approximately $600^{\circ} \mathrm{C}$ [11]. The flat glass that forms the bottom wall and the heated substrate of the APCVD horizontal reactor continuously scrolls (see Gordon [3] and Sheel and Pemble [4] for a description of the CVD deposition tools used to make the coatings on flat glass). The height of these reactors is 1 $\mathrm{cm} \leq H \leq 2.5 \mathrm{~cm}$; the width is equal to the width of the glass sheet that is 2 to $4 \mathrm{~m}$; the length between the injector and the extractor of the reactive gases can vary between $60 \mathrm{~cm}$ and $1 \mathrm{~m}$. Thus, the transversal and longitudinal aspect ratios of these APCVD reactors are very large: $80 \leq B \leq 400$ and $25 \leq A \leq 100$. The scrolling speed of the glass sheet is on the order of $0.1 \mathrm{~m} / \mathrm{s}$ [32] when the average speed of the reactive gaseous mixture is on the order of $1 \mathrm{~m} / \mathrm{s}$. Thus, the flow configuration in this reactor type is a Couette-Poiseuille-Rayleigh-Bénard flow, but with a weak Couette flow compared with the Poiseuille flow intensity.

The proposed idea to obtain transversally more uniform depositions in rectangular APCVD reactors is to perturb the longitudinal thermoconvective rolls that usually appear in this parameter range $\left(\mathrm{B}>10, \mathrm{Re}>70,3000<\mathrm{Ra}<\mathrm{O}\left(10^{5}\right), \operatorname{Pr} \approx 0.7\right)$, instead of making them disappear by lowering the pressure. Indeed, recently, Nicolas et al. [33] and Pabiou et al. [34, 35] have shown numerically and experimentally that a convective instability of the longitudinal roll flows in the PRB configuration is an unsteady periodic wavy roll flow. In this flow, the thermoconvective rolls snake in the mean flow direction. It means that, if the longitudinal 
rolls are permanently excited, by a mechanical or a thermal excitation for instance, unsteady wavy rolls may develop. Thus, the proposed idea is to adequately excite the longitudinal rolls at channel inlet to make them wavy and unsteady, in order to get uniform time averaged heat and mass transfers. The objective of the paper is to verify if, with such unsteady flows, uniform time averaged vapor depositions can be achieved.

The analysis is made by three-dimensional (3D) direct numerical simulations, using simplified models for the rectangular CVD reactor, the transport equations, the chemical system and the reaction kinetics. The CVD reactor is a horizontal channel of constant rectangular cross section, uniformly heated from below (on the substrate) and cooled from above. The heated substrate is fixed: the possible Couette flow is neglected beside Poiseuille flow. Note however that the results would be similar if the Couette flow was taken into account because Couette-Rayleigh-Bénard flows and PRB flows are both thermal convection with shear flows and the stability of their flow patterns are very similar (see Kelly [20] and Clever and Busse [36]): in particular, the transversal, longitudinal and wavy roll flows are present in both cases and the critical Rayleigh and Reynolds numbers are of the same order (Re is based on the velocity difference between the top and bottom plate in the Couette flows). In the present simulations, the models used to simulate the flows, the mass and heat transfers are the same as those proposed by Chiu et al. [37]. In particular, the flow model is the NavierStokes equation under the Boussinesq approximation with the physical properties computed at the arithmetic average temperature, as partly justified by Chiu et al. [37] and Wang et al. [38]. Only one heterogeneous reaction on the substrate is taken into account. It is well known that this reaction can be controlled either by the kinetics of the reaction or by the mass diffusion of the reacting species towards the substrate (see Mahajan [7] for instance). These two regimes are characterized by the surface Damköhler number Da. Da is a dimensionless number that can be considered as the ratio of the characteristic time of the mass diffusion of the reactive 
gases to the substrate to the characteristic time of the surface reaction. Its value varies from $10^{-3}$ to $10^{3}$ in $\mathrm{CVD}$ systems, with $\mathrm{Da}>1$ representing the domain where the surface reaction is controlled by the diffusion and the mass transport, and with $\mathrm{Da}<1$ representing the domain where the surface reaction is controlled by the kinetics of the reaction. When $D a<1$, the deposited layer shape is very few dependent on the flow structure. In this case, in a rectangular CVD reactor, the deposition uniformity in the spanwise direction is always very good. There is therefore no need to control the flow pattern as is proposed above. On the other hand, when $D a>1$, the deposited layer shape is completely controlled by the flow structure. This is therefore the case we are interested in here. In that aim, we have chosen the heterogeneous reaction proposed by Pons and Baillet [39] because it gives $5.6<D a<7.1$ in the simulation conditions of the present paper. It corresponds to silicon deposition from diluted silane in hydrogen, following the reaction scheme: $\mathrm{SiH}_{4}(g) \rightarrow \mathrm{Si}(\mathrm{s})+2 \mathrm{H}_{2}(\mathrm{~g})$, where $(g)$ and $(\mathrm{s})$ refer to gas and solid states respectively.

In the following, the mathematical formulation of the treated problem, comprising the channel geometry, the model equations, the boundary conditions and the kinetics model of the heterogeneous chemical reaction, is first given and the adopted hypotheses are discussed. Then, the numerical method used to solve the model and validation results are presented. In the last section, the numerical results are analysed by comparing the shape of the time averaged deposition rates of silicon obtained with longitudinal and wavy roll flows for three sets of Rayleigh and Reynolds numbers: $(\mathrm{Ra} ; \mathrm{Re})=(10000 ; 150),(20000 ; 150)$ and $(10000 ; 80)$.

\section{Mathematical model}

\subsection{Geometry and governing equations}

The horizontal CVD reactor considered in this study is shown in Figure 1. It is a horizontal 
rectangular channel of height $\mathrm{H}$, width 1 and length $\mathrm{L}$, heated from below. The cold top wall is maintained at the ambient temperature $T_{c}$ and the susceptor on the bottom wall is heated at a higher temperature $T_{h}$. Upstream the susceptor, the bottom plate in the entrance zone of length $\mathrm{L}_{\mathrm{e}}$ is either adiabatic or cooled at $\mathrm{T}_{\mathrm{c}}$. The vertical lateral walls are adiabatic. The origin of the reference frame being placed at the beginning of the heated plate, the computational domain is defined by $(\mathrm{x}, \mathrm{y}, \mathrm{z}) \in\left[-\mathrm{A}_{\mathrm{e}}, \mathrm{A}-\mathrm{A}_{\mathrm{e}}\right] \times[0, \mathrm{~B}] \times[0,1]$ in dimensionless Cartesian coordinates, where $\mathrm{A}=\mathrm{L} / \mathrm{H}$ and $\mathrm{B}=1 / \mathrm{H}$ are the streamwise and spanwise aspect ratios of the channel and $\mathrm{A}_{\mathrm{e}}=\mathrm{L}_{\mathrm{e}} / \mathrm{H}$ is the streamwise entrance aspect ratio. A pressure-driven Poiseuille flow of a gaseous binary mixture made of silane $\left(\mathrm{SiH}_{4}\right)$, as a precursor, diluted in hydrogen, as neutral carrier gas, enters into the reactor at the ambient temperature $T_{c}$, with the average velocity $\mathrm{U}_{\text {mean. }}$ The mass fraction of silane at the entrance is equal to $\Omega_{0}$ and that of hydrogen is equal to $1-\Omega_{0}$. As the gaseous mixture flows over the susceptor, the mass fraction of silane decreases downstream due to the adsorption of silicon on the susceptor.

To simulate the thermoconvective flows in this reactor, the $\mathrm{H}_{2} / \mathrm{SiH}_{4}$ binary mixture is considered as a Newtonian fluid governed by the 3D incompressible Navier-Stokes equations under the Boussinesq approximations. In particular, the density in the buoyancy term is $\rho=\rho^{\circ}\left(1-\beta^{\circ}\left(\mathrm{T}-\mathrm{T}_{\mathrm{c}}\right)\right)$, with $\beta^{\circ}$ the thermal expansion coefficient considered as constant. This model is shown to be valid for the present study because the thicknesses of the different boundary layers and, as a consequence, the heat and mass transfers on the substrate, are not fundamentally modified by considering constant physical properties instead of variable with temperature. The validity of this model is discussed in details in $\S 2.5$. The reactive gas $\left(\mathrm{SiH}_{4}\right)$ is considered as much diluted in the carrier gas $\left(\mathrm{H}_{2}\right)$ so that the dilute approximations can be applied (see Bird and al. [40]). Thus, as it is often done for the simulation of many CVD systems (see Mahajan [7], Chiu et al. [37], Pons and Baillet [39]), Dufour effect, viscous dissipation, pressure work, heat of reaction in the energy equation, Soret effect and the 
formation or destruction of the species due to homogeneous reactions in the species equation are neglected. A priori, there is no reason to neglect Soret effect for a mixture of two gases when the molecular mass ratio and the temperature difference in the channel are large, as is the case here with the $\mathrm{H}_{2} / \mathrm{SiH}_{4}$ mixture in a CVD reactor. However, as will be shown at the end of $\$ 4$, we have verified that Soret effect can all the same be neglected in the present study.

Giving the following reference quantities: $H, U_{\text {mean }}, H / U_{\text {mean }}, \rho^{\circ} U_{\text {mean }}{ }^{2}$ and $\Omega_{0}$ for the lengths, the mixture velocity, the time, the mixture pressure and the silane mass fraction respectively, and defining the mixture reduced temperature $\theta=\left(T-T_{c}\right) /\left(T_{h}-T_{c}\right)$, the dimensionless governing equations for continuity, momentum, energy and species are as follows:

$$
\begin{aligned}
& \nabla \cdot \overrightarrow{\mathrm{v}}=0 \\
& \frac{\partial \overrightarrow{\mathrm{v}}}{\partial \mathrm{t}}+(\overrightarrow{\mathrm{v}} \cdot \nabla) \overrightarrow{\mathrm{v}}=-\nabla \mathrm{p}+\frac{1}{\operatorname{Re}} \nabla^{2} \overrightarrow{\mathrm{v}}+\frac{\mathrm{Ra}}{\operatorname{Re}^{2} \operatorname{Pr}} \theta \overrightarrow{\mathrm{k}} \\
& \frac{\partial \theta}{\partial \mathrm{t}}+\overrightarrow{\mathrm{v}} \cdot \nabla \theta=\frac{1}{\operatorname{RePr}} \nabla^{2} \theta \\
& \frac{\partial \omega}{\partial \mathrm{t}}+\overrightarrow{\mathrm{v}} \cdot \nabla \omega=\frac{1}{\operatorname{ReSc}} \nabla^{2} \omega\left(+\frac{\alpha_{\mathrm{T}}^{\circ}}{\operatorname{ReSc}} \nabla \cdot\left\{\omega\left(1-\Omega_{0} \omega\right) \nabla[\ln \mathrm{T}]\right\}\right)
\end{aligned}
$$

where $\overrightarrow{\mathrm{v}}=(\mathrm{u}, \mathrm{v}, \mathrm{w})$ is the mixture velocity vector, $\overrightarrow{\mathrm{k}}$ the upward unit vector, $\mathrm{p}$ the deviation of the mixture pressure from the hydrostatic pressure, $\omega$ the reduced mass fraction of silane, Re the Reynolds number $\left(=\mathrm{U}_{\text {mean }} \mathrm{H} / v^{\circ}\right)$, Ra the Rayleigh number $\left(=\mathrm{g} \beta^{\circ}\left(\mathrm{T}_{\mathrm{h}}-\mathrm{T}_{\mathrm{c}}\right) \mathrm{H}^{3} /\left(v^{\circ} \alpha^{\circ}\right)\right), \operatorname{Pr}$ the Prandtl number $\left(=v^{\circ} / \alpha^{\circ}\right)$ and Sc the Schmidt number $\left(=v^{\circ} / \mathrm{D}^{\circ}\right)$. The mixture density $\rho^{\circ}$, the thermal expansion coefficient $\beta^{\circ}$, the kinematic viscosity $v^{\circ}$, the thermal diffusivity $\alpha^{\circ}$, the ordinary binary diffusion coefficient of silane into hydrogen $\mathrm{D}^{\circ}$ and the thermal diffusion factor $\alpha_{T}{ }^{\circ}$ are all evaluated at the arithmetic average temperature $\mathrm{T}^{\circ}=\left(\mathrm{T}_{\mathrm{h}}+\mathrm{T}_{\mathrm{c}}\right) / 2$. The last term in brackets in equation (4) is the Soret effect term. It is introduced in the model only once at the end of the paper to test its influence on the deposition rate at $(R a ; R e)=(10000 ; 80)$. It is deactivated in all other cases. 


\subsection{Boundary conditions}

At the inlet, the velocity profile of the $\mathrm{H}_{2} / \mathrm{SiH}_{4}$ mixture is a "3D" Poiseuille profile. The analytical expression of this profile is given by Shah and London [41] and the details of its computation can be found in Nicolas et al. [27]. By noting $\mathrm{u}_{\mathrm{Pois}}(\mathrm{y}, \mathrm{z})$ its dimensionless form, the inlet boundary conditions are the following:

$$
\text { at } \mathrm{x}=-\mathrm{A}_{\mathrm{e}}, \mathrm{u}=\mathrm{u}_{\text {Pois }}(\mathrm{y}, \mathrm{z}), \mathrm{v}=\mathrm{w}=0, \theta=0 \text { and } \omega=1 \text {. }
$$

The cold or adiabatic horizontal and vertical walls are impermeable non-reacting walls. The mass flux is zero at these walls and no-slip conditions are imposed:

$$
\begin{aligned}
& \text { at } \mathrm{y}=0 \text { and } \mathrm{B}, \overrightarrow{\mathrm{v}}=\overrightarrow{0}, \partial \theta / \partial \mathrm{y}=0 \text { and } \partial \omega / \partial \mathrm{y}=0 \text {; } \\
& \text { at } \mathrm{z}=0 \text {, for } \mathrm{x} \in\left[-\mathrm{A}_{\mathrm{e}}, 0\right], \overrightarrow{\mathrm{v}}=\overrightarrow{0}, \theta=0 \text { or } \partial \theta / \partial \mathrm{z}=0 \text { and } \partial \omega / \partial \mathrm{z}=0 \text {; } \\
& \text { at } \mathrm{z}=1, \overrightarrow{\mathrm{v}}=\overrightarrow{0}, \theta=0 \text { and } \partial \omega / \partial \mathrm{z}=0 \text {. }
\end{aligned}
$$

On the reacting bottom plate, i.e. on the isothermally heated surface of the susceptor, the mass transfer is obtained by performing the mass balance on silicon: the convective and diffusive mass fluxes of silane normal to the susceptor must be equal to the rate of disappearance of silane through the surface reaction making silicon deposition: $\mathrm{SiH}_{4} \rightarrow \mathrm{Si}+2 \mathrm{H}_{2}$. To be strictly exact, the total mass flux at the susceptor surface being different from zero, the vertical velocity component of the gaseous mixture do not vanish (see Mahajan [7] and Pons and Baillet [39]). However, for the present study, we have verified that this vertical velocity component is very low and that to neglect it does not affect the growth velocity of the silicon layer and the stability of the numerical scheme. Thus, as is done by Chiu et al. [37], the following boundary conditions are taken at the susceptor surface:

$$
\text { at } \mathrm{z}=0 \text {, for } \mathrm{x} \in\left[0, \mathrm{~A}-\mathrm{A}_{\mathrm{e}}\right], \overrightarrow{\mathrm{v}}=\overrightarrow{0}, \theta=1 \text { and } \partial \omega / \partial \mathrm{z}=\mathrm{Da} R / \mathbb{R}_{0} \text {, }
$$

where $\mathbb{R}=\mathbb{R}(\omega)$ is the reaction rate of silane on the substrate (see $\S 2.3$ ), $\mathbb{R}_{0}=\mathbb{R}(1)$ is the reaction rate computed for the reduced inlet mass fraction $\omega_{0}=1$ and $\mathrm{Da}=\mathrm{H} \mathbb{R}_{0} /\left(\rho^{\circ} \mathrm{D}^{\circ} \Omega_{0}\right)$ is the surface Damköhler number. When the Soret effect is introduced in the model, the $\omega$ boundary 
conditions change on the horizontal cold wall and on the substrate. They become:

$$
\begin{aligned}
& \text { at } z=1, \partial \omega / \partial \mathrm{z}+\alpha_{\mathrm{T}}{ }^{\circ} \omega\left(1-\Omega_{0} \omega\right)(\partial[\ln \mathrm{T}] / \partial \mathrm{z})=0 \\
& \text { at } z=0, \text { for } x \in\left[0, A-A_{e}\right], \partial \omega / \partial \mathrm{z}+\alpha_{\mathrm{T}}{ }^{\circ} \omega\left(1-\Omega_{0} \omega\right)(\partial[\ln \mathrm{T}] / \partial \mathrm{z})=\mathrm{Da} R / R_{0}
\end{aligned}
$$

At the outlet, a non-reflective boundary condition adapted from Orlanski [42] is used for u, v, $\mathrm{w}$ and $\theta$ and the gradient of $\omega$ is set equal to zero:

at $\mathrm{x}=\mathrm{A}-\mathrm{A}_{\mathrm{e}}, \partial \mathrm{f} / \partial \mathrm{t}+\partial \mathrm{f} / \partial \mathrm{x}=0$ for $\mathrm{f}=\mathrm{u}, \mathrm{v}, \mathrm{w}$ and $\theta$ and $\partial \omega / \partial \mathrm{x}=0$.

\subsection{Reaction rate and deposition rate}

The reaction rate $\mathscr{R}$ of silicon on the substrate is a semi-empirical datum given in $\left[\mathrm{kg} / \mathrm{m}^{2} \mathrm{~s}\right]$. In real silicon CVD reactors, there are usually several reactive species and numerous homogeneous and heterogeneous reactions. To get a realistic silicon growth rate with a simplified CVD model using a binary mixture like the $\mathrm{H}_{2} / \mathrm{SiH}_{4}$ mixture, the reaction rate $\mathcal{R}$ is usually adapted to express the deposition behaviour resulting from the whole species and reactions. This is what is proposed by Pons and Baillet [39]. Their reaction rate $\mathcal{R}$ writes:

$$
R=\gamma_{\mathrm{SiH}_{4}} \rho_{\mathrm{h}} \omega_{\mathrm{SiH}_{4}} \Omega_{0} \sqrt{\frac{\mathrm{RT}_{\mathrm{h}}}{2 \pi \mathrm{M}_{\mathrm{SiH}_{4}}}}
$$

where $\gamma_{\mathrm{SiH} 4}=4.017 \times 10^{-2} \exp \left(-5021 / \mathrm{T}_{\mathrm{h}}\right)$ is the silane sticking coefficient, i.e. its probability to deposit on the substrate for a given temperature, $\rho_{h}=\rho\left(T_{h}\right)$ is the mixture density at substrate temperature, $\mathrm{R}=8.314 \mathrm{~J} /(\mathrm{mol} . \mathrm{K})$ is the universal gas constant and $\mathrm{M}_{\mathrm{SiH} 4}=32.12 \mathrm{~g} / \mathrm{mol}$ is the silane molecular weight. As already mentioned, for the flow parameters of the present study, the reaction rate (5) corresponds to high Damköhler numbers (5.6 $\leq \mathrm{Da} \leq 7.1)$.

In the following, the uniformity of the deposition will be analysed from the time average deposition rate of silicon, $<\mathrm{G}>$, at the susceptor surface. This quantity is defined from the local deposition rate of silicon, G. It expresses the molar balance between silane and silicon in 
the heterogeneous reaction at the susceptor surface. $\mathrm{G}$ and $<\mathrm{G}>$ are defined by:

$$
\mathrm{G}=\frac{\mathrm{M}_{\mathrm{Si}} \mathcal{R}}{\mathrm{M}_{\mathrm{SiH}_{4}} \rho_{\mathrm{Si}}} \quad ; \quad<\mathrm{G}>=\frac{1}{\mathcal{T}} \int_{\mathrm{t}_{0}}^{\mathrm{t}_{0}+\mathcal{T}} \mathrm{G} \mathrm{dt}
$$

with the time $\mathcal{T}$ long enough to get constant time averages. For the sinuous roll flows, $\mathcal{T}$ will be equal to five time periods of the sinuous rolls. Note that, after a flow time long enough, the shape of the deposition (its thickness) can be likened to the shape of the average deposition rate $<\mathrm{G}>$, since the former is obtained by the time integration of the latter. $\mathrm{G}$ and $<\mathrm{G}>$ are generally given in $[\mu \mathrm{m} / \mathrm{min}]$.

\subsection{Physical properties and flow parameters}

To evaluate the reference density $\rho^{\circ}=\rho\left(T^{\circ}\right)$ and $\rho_{h}=\rho\left(T_{h}\right)$ in equation (5), the gaseous mixture is considered as an incompressible ideal gas: $\rho=P_{0} M /(R T)$, where $P_{0}$ is the inlet mixture pressure and $\mathrm{M}=\left(\Sigma_{\mathrm{i}}\left(\omega_{\mathrm{i}} / \mathrm{M}_{\mathrm{i}}\right)\right)^{-1}$ is the mixture molecular weight, with $\mathrm{i}=\left(\mathrm{SiH}_{4}, \mathrm{H}_{2}\right) . \mathrm{P}_{0}$ can be considered equal to the atmospheric pressure and constant in the whole reactor because the pressure variation is negligible in an open channel such as those investigated in the present study. As proposed by Chiu et al. [37] and Wang et al. [38], the physical properties of the mixture are computed at the arithmetic average temperature $T^{\circ}$. In the present paper, $v^{\circ}, \alpha^{\circ}$, $\mathrm{C}_{\mathrm{p}}{ }^{\circ}$ and $\mathrm{D}^{\circ}$ are computed from the $\mathrm{H}_{2}$ and $\mathrm{SiH}_{4}$ properties, evaluated at atmospheric pressure, $\mathrm{T}^{\circ}=600 \mathrm{~K}$ and $\Omega^{\circ}=2 \%$, using the data collected by Mahajan [7] (in Table 1, page 363 and formulae (65-68), page 365, of reference [7]). The values of the thermal diffusion factor $\alpha_{T}^{\circ}$ for diluted silane in hydrogen (or nitrogen) are extracted from Holstein [43]. $\beta^{\circ}=1 / \mathrm{T}^{\circ}$ since the gaseous mixtures are considered as ideal gases. All these properties are given in table 1 with those of the $\mathrm{N}_{2} / \mathrm{SiH}_{4}$ mixture for comparisons.

In the present paper, $\mathrm{T}^{\circ}=600 \mathrm{~K}$ because the silicon depositions are compared for six different 
PRB flows of a $\mathrm{H}_{2} / \mathrm{SiH}_{4}$ mixture injected into the reactor at $\mathrm{T}_{\mathrm{c}}=300 \mathrm{~K}$, at atmospheric pressure, with the silane mass fraction $\Omega_{0}=2 \%$ and with the substrate heated at $\mathrm{T}_{\mathrm{h}}=900 \mathrm{~K}$. The six PRB flows correspond to three different flow classes, defined by the parameters given in table 2 , each class comprising two different flow types. The first flow type is the steady longitudinal roll flow that naturally develops without introducing any excitation into the channel. The second one is the unsteady wavy roll flow that develops when exciting the first flow type with a sinusoidal excitation at the channel inlet. More precisely, the excitation is introduced on the dimensionless transversal velocity component, v, at mid-height of the inlet Poiseuille profile: at $\mathrm{x}=0, \mathrm{v}=0$ everywhere, except at $\mathrm{z}=0.5$ where $\mathrm{v}=\mathrm{vexc} \times \cos (2 \pi \mathrm{ft})$. The used values of the excitation magnitude, $\mathrm{v}_{\mathrm{exc}}$, and of its dimensionless frequency, $\mathrm{f}$, are given in table 2 . As shown by Benzaoui et al. [44, 45], these values correspond to well amplified wavy rolls for the tested flow parameters. This excitation approximately simulates the transversal oscillation of a horizontal thin rod placed at channel mid-height, just upstream the susceptor.

As shown in table 2, the three simulated flow classes corresponds to $(R a, R e)=(10000,150)$ for case $1,(R a, R e)=(20000,150)$ for case 2 and $(R a, R e)=(10000,80)$ for case 3 . For the $\mathrm{H}_{2} / \mathrm{SiH}_{4}$ mixture properties listed in table $1, \mathrm{Pr}=0.68$ and $\mathrm{Sc}=1.76$. In table 2, the quantities noted with a standard font are those directly introduced in the model, while the italic ones are deduced from the first ones, from the properties of table 1 and from equation (5) concerning Da. It can then be shown that the simulated flows correspond to channel heights $5.6 \leq H \leq 7.1$ $\mathrm{cm}$ and mean velocities $0.48 \leq U_{\text {mean }} \leq 0.91 \mathrm{~m} / \mathrm{s}$, which are realistic quantities [12]. Note that, in the APCVD reactors used in the float glass processes, the carrier gas is more often nitrogen or air. In this case, for a $\mathrm{N}_{2} / \mathrm{SiH}_{4}$ mixture for instance, since the product $v^{\circ} \alpha^{\circ}$ is fifty times smaller than for the $\mathrm{H}_{2} / \mathrm{SiH}_{4}$ mixture (see table 1), it can be shown that the tested values of the Rayleigh number correspond to channel heights $1.5 \leq H \leq 1.9 \mathrm{~cm}$, which are the usual heights of this reactor type. 


\subsection{Validity of the Boussinesq approximation}

In spite of the great temperature difference in the present study $\left(\varepsilon=\left(T_{h}-T_{c}\right) / T_{c}=2\right)$, the Boussinesq approximation is adopted on the basis of the works of Wang et al. [38] and Chiu et al. [37]. Indeed, Wang et al. [38] have numerically investigated 3D PRB flows using both a variable property (VP) formulation (full model) and several constant property formulations (Boussinesq models) with different reference temperatures to evaluate the physical properties of the fluid. For longitudinal roll flows in air, with $50 \leq \mathrm{Re} \leq 200$ and $0.03 \leq \varepsilon \leq 2.33$, they show that the VP formulation and the constant property formulation with $\mathrm{T}^{\circ}$ as reference temperature (noted $\mathrm{CP}\left(\mathrm{T}^{\circ}\right)$ here) qualitatively give the same flow structure. $\mathrm{The} \mathrm{CP}\left(\mathrm{T}^{\circ}\right)$ model is acceptable to evaluate the heat transfer since the Nusselt number difference under the VP and $\mathrm{CP}\left(\mathrm{T}^{\circ}\right)$ formulations is less than $16 \%$. Chiu et al. [37] have numerically investigated the validity of the $\mathrm{CP}$ formulation in comparison with the VP one, in the case of the CVD modelling of the silicon deposition, in 2D rectangular reactors, using the $\mathrm{H}_{2} / \mathrm{SiH}_{4}$ mixture. For $\mathrm{T}_{\mathrm{c}}=300 \mathrm{~K}, 900 \mathrm{~K} \leq \mathrm{T}_{\mathrm{h}} \leq 1323 \mathrm{~K}, 2 \leq \varepsilon \leq 3.41$ and $3.83 \times 10^{-3} \leq \mathrm{Da} \leq 2.19$, they show that the $\mathrm{CP}\left(\mathrm{T}^{\circ}\right)$ model predicts the deposition rate of silicon with less than $6 \%$ deviation from the VP model over the range of temperature considered. Since, in our study, the conditions are very close to those of $[37,38]$ (see table 2 ) and since we are mainly interested in the shape of the vapor depositions resulting from particular flow patterns, the results of the present paper will be able to be considered as qualitatively valid and the analysis as pertinent.

\section{Numerical methods and validations}

The system of equations (1-4) with the boundary conditions of section 2.2 is solved using a very efficient finite difference method which is optimized for vectorial computers. The time discretization scheme is the second-order Adams-Bashforth scheme. The equations are 
discretized in space on uniform, Cartesian and staggered grids by a second-order central scheme for the diffusive terms and a second order upwind scheme for the convective terms. The time integration and the velocity-pressure coupling are computed by Goda's algorithm [46]. It is a projection method which consists in two main steps: prediction and projection. In the prediction step, after having obtained the temperature field, an approximated nondivergence-free velocity field is computed by solving three Helmholtz equations (one for each velocity component) obtained by explicitly treating the pressure gradient in the momentum equation. In the projection step, the non-divergence-free velocity field is projected into a divergence-free subspace. This projection results from the application of the incompressibility constraint and is done by solving a Poisson equation for the pressure increment between two time steps. Thus, during one time step, the energy equation (3) is first solved, then the momentum equation (2), under the incompressibility constraint (1) and the species equation (4) at the end. The temperature and silane mass fraction fields are obtained by solving Helmholtz equations. Therefore, at each time step, five Helmholtz equations and one Poisson equation have to be solved. The Helmholtz equations are solved using an incremental factorization method of ADI type which permits to keep a second order time accuracy (see Benzaoui et al. [45] for more details). The Poisson equation is also solved by a factorization method which consists in the partial diagonalization of the mono-dimensional Laplace operators in the transversal directions y and $\mathrm{z}$. The linear systems resulting from these two factorization methods are all tridiagonal and are solved by the TDMA algorithm. Since this solver is highly vectorisable, the code is very efficient on the used vectorial supercomputer, a NEC-SX5 computer: it runs at 6 GigaFloaps on average, when the crest power of this computer is 8 Giga Floaps. Furthermore, the 3D unsteady computations with vapor deposition presented in this paper, on grids of 3.6 million nodes (see table 2), with a dimensionless time step $\Delta \mathrm{t}=0.01$, have required less than 10 hours of CPU time. 
The single species version of the present code has been used to simulate mixed convection flows (see Nicolas et al. [33] and Pabiou et al. [34]) and a detailed validation of this code is presented in Benzaoui et al. [45]. The second order space and time accuracies of the computed solutions are verified. The code is also validated through comparisons with experimental measurements made for PRB flows, concerning steady longitudinal rolls in nitrogen, both unsteady transverse and steady longitudinal rolls in water and convectively unstable wavy rolls in an air channel [35]. The code is shown to be able to finely reproduce these experimental works. We therefore consider here that it is validated to simulate the flows and the heat transfers in rectangular CVD reactors.

To validate the implementation of the species equation and the model of surface deposition in the code, the numerical results have been compared with analytical solutions and excellent agreement has been obtained (see Benzaoui [47] for the details). Furthermore, comparisons with the experimental measurements of Eversteyn et al. [48] and with the $2 \mathrm{D}$ numerical simulations of Chiu et al. [37] and Chiu and Jaluria [49] have been performed. These experiments and simulations evaluate the deposition rate of silicon in the horizontal rectangular CVD reactor presented in figure 2. In this reactor, a $\mathrm{H}_{2} / \mathrm{SiH}_{4}$ gaseous mixture at atmospheric pressure enters into the reactor at the average velocity $U_{\text {mean }}=0.175 \mathrm{~m} / \mathrm{s}$, with the dimensionless Poiseuille profile $\mathrm{u}=6\left[\mathrm{z}-\mathrm{z}^{2}\right]$, at the silane partial pressure $\mathrm{P}_{\mathrm{SiH} 4}=124.1 \mathrm{~Pa}$, $\mathrm{T}_{\mathrm{c}}=300 \mathrm{~K}$ and $\Omega_{0}=2 \%$. The substrate temperature is $\mathrm{T}_{\mathrm{h}}=1323 \mathrm{~K}$. Compared with equation (5), another heterogeneous reaction rate $\mathcal{R}^{\prime}$ is used. It corresponds to the silane reaction rate for the silicon deposition in a pure $\mathrm{H}_{2}-\mathrm{SiH}_{4}$ system. It is given by :

$$
\mathbb{R}^{\prime}=\frac{1.25 \times 10^{9} \exp \left(-18452 / \mathrm{T}_{\mathrm{h}}\right) \mathrm{M}_{\mathrm{SiH}_{4}} \mathrm{P}_{\mathrm{SiH}_{4}}}{1+1.75 \times 10^{3} \mathrm{P}_{\mathrm{H}_{2}}+4 \times 10^{4} \mathrm{P}_{\mathrm{SiH}_{4}}}
$$

where the partial pressures $\mathrm{P}_{\mathrm{SiH} 4}$ and $\mathrm{P}_{\mathrm{H} 2}$ are in [atm] and the susceptor temperature $\mathrm{T}_{\mathrm{h}}$ is in Kelvin. The mathematical model is the Boussinesq model without Soret effect presented 
herein but the constant physical properties are computed at the "integral average temperature" (see [37, 49] for its definition). The dimensionless parameters are $\mathrm{Re}=11.8, \mathrm{Ra}=94.6, \mathrm{Pr}=0.66$ and $\mathrm{Sc}=1.54$. To be able to reproduce the $2 \mathrm{D}$ numerical simulations of Chiu et al. [37] and Chiu and Jaluria [49], slip conditions are imposed on the vertical lateral walls in our 3D code: the spanwise velocity component $\mathrm{v}$ is zero and Neuman boundary conditions are imposed on $\mathrm{u}, \mathrm{w}, \mathrm{T}$ and $\omega$. The number of nodes in the spanwise direction is also reduced at 5 nodes to avoid the appearance of potential three-dimensional flow patterns. The mesh size is $\mathrm{N}_{\mathrm{x}} \times \mathrm{N}_{\mathrm{y}} \times \mathrm{N}_{\mathrm{z}}=500 \times 5 \times 40$ (where $\mathrm{N}_{\mathrm{i}}$ is the mesh size in the space direction i). The deposition rates of silicon along the susceptor, measured by Eversteyn et al. [48] and computed by Chiu et al. [37] and by the present study are presented in figure 3 . The results of the $2 \mathrm{D}$ numerical simulations are in a very good accordance with each other and in qualitative agreement with the experiments. We therefore consider that our code is fully validated.

\section{Analysis of the results}

According to the temporal linear stability analysis of Clever and Busse [28] and Xin et al. [50], the numerical simulations and the experiments of Nicolas et al. [33], Pabiou et al. [34, 35] and Benzaoui et al. [45], it is well known that a convective instability of the steady longitudinal rolls in a PRB flow is an unsteady wavy (or sinuous) roll flow in which the thermoconvective rolls snake in the mean flow direction. In the case of air flows $(\operatorname{Pr}=0.7)$ and channels of large spanwise aspect ratio $(B \geq 10)$ in which a permanent excitation is sustained (by a mechanical agitator at channel inlet, for instance), the wavy rolls develop approximately for $80<\operatorname{Re}(<1000)$ and $3000<\operatorname{Ra}(<30000)$ (the upper limits are not yet clearly defined). The wave length, time period, amplitude and space growth rate of the wavy rolls vary with Ra and Re and with the frequency and the amplitude of the excitation. Pabiou et al. [35] and Benzaoui et al. [44, 47] determined the agitator parameters to get well and fully amplified 
wavy rolls, with high space growth rates, for $\operatorname{PRB}$ flows at $\operatorname{Pr}=0.7, \mathrm{~B}=10,100 \leq \mathrm{Re} \leq 174$ and $6300 \leq \mathrm{Ra} \leq 9000$. In view of these results, we have empirically fixed the agitator parameters for the flow of the present study to get well amplified wavy rolls (see table 2).

For each of the three flow classes presented in table 2, two flow types are simulated: (i) without excitation in the channel and (ii) with sinusoidal excitation at inlet. In a first step, these two flow types are computed until they are fully-established, that is steady for the former flow type and oscillating, with space and time periodicity, for the latter one. The temperature fields on the horizontal mid-plane of the six resulting flows are presented in figure 4. The red lines (the clear lines with a darker center) correspond to the ascending hot fluid and the blue lines (the thin dark lines) to the descending cold fluid: there is thus two contrarotative rolls between two red lines. Thus, ten steady longitudinal rolls develop in the case without excitation (figures $4(\mathrm{a}, \mathrm{c}, \mathrm{e})$ ) and ten wavy rolls develop in the excited case (figures 4(b, d, f)). At the higher Rayleigh number ( $\mathrm{Ra}=20000$ for the case 2 of table 2), with no excitation (figure 4(c)), a steady varicose small deformation appears in the longitudinal rolls. The longitudinal rolls (figures $4(\mathrm{a}, \mathrm{c}, \mathrm{e})$ ) first appear from the vertical walls, at the beginning of the heated substrate. They invade the channel towards the center like a gearing, making appear a triangular zone upstream (for $x \leq 30$ in figure $4(a)$ for instance). In this zone, the flow is a forced convection flow which is nearly parallel to the horizontal walls. The length of this zone decreases when Re decreases and Ra increases. From their experiments in an air channel of transversal aspect ratio $B=10.38$, Pabiou et al. [35] give the following correlation for the dimensionless coordinate of the end of this zone on the channel axis:

$$
\mathrm{x}_{\mathrm{R}_{/ /}}=1.68 \mathrm{Re}^{0.79}\left(\frac{\mathrm{Ra}-\mathrm{Ra}_{/ /}^{*}}{\mathrm{Ra}_{/ /} *}\right)^{-0.67}
$$

where $R a_{/ /}^{*}=1708$ is the critical Rayleigh number for the appearance of the longitudinal rolls. Thus, using correlation (8) that is valid for $90 \leq R e \leq 310$ and $4500 \leq R a \leq 9900$, we get 
$\mathrm{x}_{\mathrm{R}_{/ /}}=30.5$ and 18.6 in the cases 1 and 3 of table 2, respectively, which is in good agreement with what is observed in figures 4(a) and 4(e). As already said, the wavy rolls of the excited flows are an instability of the longitudinal rolls. Therefore the length of appearance of the wavy rolls is necessarily higher than for the longitudinal rolls. This length is a function of Ra, Re and of the agitator parameters ( $f$ and $\left.v_{\text {exc }}\right)$. On figures $4(b, d, f)$, we can approximately measure the growth length $\mathrm{x}_{\mathrm{R}_{\approx}}$ of the wavy rolls till saturation: $\mathrm{x}_{\mathrm{R}_{\approx}} \approx 90$ for case $1, \mathrm{x}_{\mathrm{R}_{\approx}} \approx 70$ for case 2 and $\mathrm{x}_{\mathrm{R}_{\approx}} \approx 20$ for case 3. The fact that $\mathrm{x}_{\mathrm{R}_{\approx}}=\mathrm{x}_{\mathrm{R}_{/ /}}$in this latter case could be attributed to the amplitude of the inlet excitation on the transversal velocity that is equal to four times the average flow velocity (see table 2). However, we have verified that $\mathrm{x}_{\mathrm{R}_{\approx}}=\mathrm{x}_{\mathrm{R}_{/ /}} \approx 20$ even with $v_{\text {exc }}=2$. In case 3 of table 2 , we chose $v_{\text {exc }}=4$ because the oscillation amplitude of the wavy rolls are a bit higher with $v_{\text {exc }}=4$ than with $v_{\text {exc }}=2$. In the three sinuous roll flows of figure 4, the frequency of the wavy rolls is equal to the frequency of the inlet excitation. Furthermore, the wave length of the wavy rolls is $\lambda \approx 8.8$ for case $1, \lambda \approx 8$ for case 2 and $\lambda \approx 12$ for case 3. That corresponds to an approximately constant phase velocity $c=\lambda f \approx 1.25 \pm 0.05$. All these results are coherent with the literature results obtained with little smaller Rayleigh numbers [35, 45, 50].

Once the six flows of figure 4 are fully established, the average deposition rate of silicon on the substrate, $<\mathrm{G}>$, is computed. The three-dimensional surfaces of $<\mathrm{G}>$ are presented in figure 5. Furthermore, to have a better precision, transversal profiles of $<\mathrm{G}>$ in several axial positions are extracted from figure 5 and presented in figure 6 . In the present simulated flows, since the Damköhler numbers are large ( $\mathrm{Da}=5.6$ for cases 1 and 3 and $\mathrm{Da}=7.1$ for case 2$)$, as soon as a silane molecule is close to the susceptor, it is adsorbed and the deposition shape is completely controlled by the flow structure and the transport of silane to the susceptor. In the triangular zone at the channel entrance, the flow is nearly parallel to the horizontal walls and 
the silane molecules can only reach the susceptor by downward diffusion. As a consequence (see figure 5), the deposition rate is very high at the leading edge of the susceptor $(x=1)$ because the mass fraction of silane is maximum. Just downstream, due to the silane depletion near to the susceptor, the deposition rate of silicon quickly becomes very small. The end of the diffusive triangular zone is marked by the appearance of the thermoconvective rolls, i.e. by the vertical mixing of the gaseous mixture by convection. The silane molecules located in the upper zone of the channel can go down to the susceptor between each roll pair where the fluid goes down. The reaction rate of silane strongly increases at this place. In the case of the steady longitudinal roll flows, parallel-ridge-shaped depositions are obtained (see the five parallel ridges of figures $5(\mathrm{a}, \mathrm{c}, \mathrm{e}))$. The height of the ridges decreases downstream with the silane depletion. In figure 5(c), small axial modulations of the ridges are observed because, as already mentioned, the flow presents small steady varicose oscillations at $\mathrm{Ra}=20000$.

While the ridges are present on the whole susceptor when steady parallel rolls develop (see figures $5(\mathrm{a}, \mathrm{c}, \mathrm{e})),<\mathrm{G}>$ and, as a result, the average thickness of the silicon deposition are nearly uniform where the sinuous rolls are fully-amplified, that is for $\mathrm{x}>\mathrm{x}_{\mathrm{R}_{\approx}}$ and sufficiently far from the vertical lateral walls (see figures $5(\mathrm{~b}, \mathrm{~d}, \mathrm{f})$ ). This is clearer in figure 6 where the transversal profiles of $<\mathrm{G}>$ for the longitudinal and wavy roll flows are compared. First, one can note that the relative height of the ridges is important in the three simulated longitudinal roll flows (see the continuous lines in figures 6(a-c)). Indeed, at the channel center, whatever the axial coordinate may be, the magnitude of the oscillations of $<\mathrm{G}>$ is around $75 \%$ of its average value: for instance, at $x=100$ and $4 \leq y \leq 6$ in figure $6(a)$, the oscillation magnitude is $0.03 \mu \mathrm{m} / \mathrm{min}$ when the average is $0.04 \mu \mathrm{m} / \mathrm{min}$. For the wavy roll flows, compared with the longitudinal roll flows, the $<\mathrm{G}>$ oscillation relative amplitude, in the central zone of the channel, is divided by two for $x \geq 80$ and it nearly vanishes for $x \geq 100$ in case 1 (figure $6(a)$ ). In case 2 (figure 6(b)), for a higher Rayleigh number, this relative amplitude is divided by two 
for $x \geq 60$ and becomes very small for $x \geq 80$. It is divided by two for $x \geq 20$ and becomes very small for $\mathrm{x} \geq 40$ in case 3 (figure 6(c)). This latter case is interesting in the view point of the APCVD reactors on float glass because the length with a weak uniformisation of the deposition $(15<x<40)$ is small compared with the longitudinal aspect ratio of this reactor type. Furthermore, the $\langle G\rangle$ oscillation amplitude only diminishes in the middle of the channel because the vertical lateral walls restrain the oscillation of the wavy rolls. However, the transversal expanse of the zone where weakly-amplified wavy rolls and parallel-ridgeshaped silicon deposition are present is limited. It varies between $1.5 \mathrm{H}$ (see figures $5(f)$ and $6(c))$ and $3.5 \mathrm{H}($ see figures $5(b, d)$ and $6(a, b))$ in the $y$ direction from the vertical walls. We have verified, in one simulation of reference [47], that the transversal extent of this zone does not vary with the channel transversal aspect ratio $B$ : in case 1 but with $B=20$, instead of 10 , it is still equal to 3.5H. Therefore, in the very wide APCVD reactors such as those used on float glass (where $80<B<400$ ), it can be considered that the zone where the wavy rolls are influenced by the lateral boundaries is negligible.

As announced in $\$ 2.1$, the influence of the Soret effect on the deposition shape is studied in the case 3 of table 2, that is for $R e=80$ and $R a=10000$. Figure 7 compares the transversal $<G>$ profiles in several axial positions for the longitudinal and wavy roll flows when the Soret effect is taken into account or not. Thus the continuous curves (without Soret effect) of figure 7 are the same curves as those of figure 6(c). In figure 7, it appears that the Soret effect is negligible on the deposition rate $\langle G>.<G>$ is little smaller upstream and a little higher downstream with the Soret effect than without. Indeed, with the Soret thermal diffusion, the light hydrogen molecules are attracted by the hot plate and the heavy silane molecules by the cold plate. Therefore, the silane molecules go upward in the entrance zone of the channel and $<G>$ is smaller upstream with Soret effect than without. As a consequence, the silane concentration keeps higher in the channel upstream zone and is convected downstream, 
where the silicon deposition rate $<G>$ becomes in its turn higher. In the present simulations, the thermal diffusion flux has the same magnitude as the ordinary diffusion flux. However, the Soret effect is negligible because the problem is at dominant convection. Indeed, in the species equation (4), the solutal Péclet number and the thermal diffusion Péclet number are both very high: ReSc $\geq 140$ and $R e S c / \alpha_{T} \geq 197$. Since, the maximum dimensionless vertical velocities are approximately equal to 0.35 in case 1, 0.61 in case 2 and 0.63 in case 3, we can consider here that the silicon deposition rate is completely controlled by the vertical thermoconvection and not by the ordinary and thermal diffusions.

\section{Discussion and conclusion}

In this paper, to simulate and to analyse the thin film deposition in cold wall rectangular APCVD reactors, simplified models for the flow and heat and mass transfers and for the heterogeneous reactions are used. The flow model, based on the Boussinesq approximations and on the high dilution approximations, is justified thanks to results extracted from literature $[37,38]$. In the first part of the paper, a bibliographical analysis allows identifying the flow parameters and the flow regimes encountered in this type of reactors. For the flow parameters generally imposed $(P r \approx 0.7, R e=O(100)$ and $R a>2000)$, the main flow patterns are longitudinal thermoconvective rolls that make parallel ridge shaped depositions. The solutions found in the literature to avoid this non uniform deposition type are reviewed.

In this paper, another solution based on our expertise in the control of the sinuous rolls in PRB flows [33-35, 44, 45, 50] is proposed. This alternative consists in exciting the longitudinal rolls, by a sinusoidal mechanical excitation at the channel inlet, to make them wavy, unsteady and periodic. By choosing an appropriate excitation frequency, the 3D numerical simulations show that well-amplified sinuous rolls can develop in the reactor and replace the longitudinal rolls. This generates more uniform time average deposition where the 
wavy rolls are fully developed, that is after the thermal entrance zone and sufficiently far from the lateral vertical walls of the reactor. This solution to make the deposition more uniform is shown to be worth being investigated when the surface Damköhler number is large and when the CVD reactors have large aspect ratios to allow the full amplification of the wavy rolls. This situation is found for instance in the online APCVD reactors used to make coatings on float glass. Indeed, the production line of flat glass can reach four metres wide and the channel of the on-line APCVD reactor can reach one meter long when its height varies between one and two centimetres.

In the present simulations of the APCVD reactors with wavy roll flows, a significant reduction of the height of the deposition ridges, compared with the reactors with longitudinal roll flows, is observed after an entrance zone whose longitudinal aspect ratio varies between 20 and 80. This length is probably too important for numerous applications (in electronics for instance) where smaller rectangular CVD reactors are used. However, in the present paper, the agitator parameters have been chosen in a very empirical way, without optimization. As was shown in [44] in a first try of optimization, we think that it is possible to optimize the flow parameters (Ra, Re) and the agitator parameters (the agitator type and location and the excitation frequency and amplitude) to get more amplified wavy rolls and shorter growth lengths, in particular by lowering the Reynolds number (till Re=70), by increasing the transversal excitation amplitude and by appropriately choosing the agitator frequency.

This work is a first investigation of the sinuous roll influence on the deposition structure. The used simplified mathematical models provide qualitative results but we think that they give a good idea of the real situation. For instance, we have recently verified that the longitudinal and wavy roll flow patterns still exist in case 1 of table 2 (but with the air physical properties) when the temperature dependence of the physical properties is taken into account. 


\section{Acknowledgements}

All the computations were carried out on the NEC-SX5 super computer at IDRIS (Orsay, France) under research project $n^{\circ} 61147$.

\section{References}

[1] A. Ern, V. Giovangigli, M. D. Smooke, J. Comp. Phys., 126 (1996) 21.

[2] A. Ern, V. Giovangigli, M. D. Smooke, J. Crystal Growth, 180 (1997) 670.

[3] M. Pons, C. Bernard, E. Blanquet, R. Madar, Thin Solid Films, 365 (2000) 264

[4] R. Gordon, J. Non-Crystalline Solids, 218 (1997) 81.

[5] D. W. Sheel, M. E. Pemble, Atmospheric Pressure CVD coatings on glass, Proceedings of the 4th International Conference for Coatings on Glass, Braunschweig, Germany, 2002.

[6] C. R. Kleijn, Chemical vapor deposition processes, in M. Meyyappan ed., Computational Modelling in Semiconductor Processing, Artech House, Boston, 97-229, 1995.

[7] R. L. Mahajan, Adv. Heat Trans., 28 (1996) 339.

[8] M. A. Kuczmarski, J. CVD, 2 (1993) 20.

[9] J. Meziere, M. Ucar, E. Blanquet, M. Pons, P. Ferret, L. Di Cioccio, J. Crystal Growth, $267(2004) 436$.

[10] S. Nishizawa, M. Pons, Microelectronic Eng., 83 (2006) 100

[11] R. J. McCurdy, Thin Solid Films, 351 (1999) 66-72.

[12] K. F. Jensen, E. O. Einset, D. I. Fotiadis, Annu. Rev. Fluid Mech., 23 (1991) 197.

[13] K. W. Park, H. Y. Pak, Num. Heat Trans. A, 37 (2000) 407.

[14] E. P. Visser, C. R. Kleijn, C. A. M. Govers, C. J. Hoogendoorn, L. J. Giling, J. Crystal Growth, 94 (1989) 929, and errata, 96 (1989) 732.

[15] N. K. Ingle, T. J. Mountziaris, J. Fluid Mech., 277 (1994) 249. 
[16] G. Evans, R. Greif, Int. J. Heat Mass Trans., 36 (1993) 2769

[17] I. Hosokawa, Y. Tanaka, K. Yamamoto, Int. J. Heat Mass Trans., 36 (1993) 3029

[18] R. E. Spall, J. Heat Trans., 118 (1996) 885

[19] W. L. Lin, T. F. Lin, Int. J. Heat Mass Trans. 39 (1996) 1649

[20] R. E. Kelly, Advances in Applied Mechanics, 31 (1994) 35.

[21] X. Nicolas, Int. J. Therm. Sc., 41 (2002) 961.

[22] H. K. Moffat, K. F. Jensen, J. Crystal Growth, 77 (1986) 108.

[23] H. K. Moffat, K. F. Jensen, J. Electrochemical Society, 135 (1988) 459.

[24] C. R. Kleijn, C. J. Hoogendoorn, Chem. Eng. Sc., 46 (1991) 321.

[25] G. Evans, R. Greif, Int. J. Heat Mass Trans., 32 (1989) 895

[26] G. Evans, R. Greif, Int. J. Heat Mass Trans., 34 (1991) 2039

[27] X. Nicolas, J. M. Luijkx, J. K. Platten, Int. J. Heat Mass Transfer, 43 (2000) 589.

[28] R. M. Clever, F. H. Busse, J. Fluid Mech., 229 (1991) 517.

[29] Y. Kato, K. Fujimura, Theoretical Applied Mech., 50 (2001) 327

[30] H. Koizumi, I. Hosokawa, Int. J. Heat Mass Transf., 36 (1993) 3997

[31] H. Van Santen, C. R. Kleijn, H. E. A. Van Den Akker, J. Crystal Growth, 212 (2000) 299 [32] A. Arnaud, J. Non-Crytalline Solids, 218 (1997) 12

[33] X. Nicolas, H. Pabiou, S. Xin, A. Benzaoui, S. Mergui, D. Gobin, P. Le Quéré, Mise en évidence du caractère convectivement instable des rouleaux sinueux dans les écoulements de Poiseuille-Rayleigh-Bénard, Proceedings French Heat Transfer Conf. SFT2003, Grenoble, 273-278, 2003.

[34] H. Pabiou, X. Nicolas, S. Xin, S. Mergui, Mécanique et Industries, 4 (2003) 537.

[35] H. Pabiou, S. Mergui, C. Bénard, J. Fluid Mech., 542 (2005)175.

[36] R. M. Clever, F. H. Busse, J. Fluid Mech., 234 (1992) 511.

[37] W. K. S. Chiu, Y. Jaluria, G. N. Glumac, Num. Heat Trans. A, 37 (2000) 113.

[38] Q. Wang, H. Yoo, Y. Jaluria, Int. J. Heat Mass Trans., 46 (2003) 297. 
[39] M. Pons, F. Baillet, Modélisation des phénomènes couplés en CVD, in A. Galerie ed., Traitements de surfaces en phase vapeur, Hermès, Lavoisier, Cachan, France, 2002, chap. 6, p. 211-259.

[40] R. B. Bird, W. E. Stewart, E. N. Lightfoot, Transport Phenomena, John Wiley \& Sons, New York, 1960.

[41] R. K. Shah, A. L. London, Laminar Flow Forced Convection in Ducts, in Advances in Heat Transfer, T. F. Irvine and J. P. Hartnett eds., Academic press, New York, 1978.

[42] I. Orlanski, J. Comp. Phys., 21 (1976) 251.

[43] W. L. Holstein, J. Electrochem. Soc., 135 (1988) 1788.

[44] A. Benzaoui, X. Nicolas, S. Xin, Numerical characterization of wavy thermoconvective patterns in Poiseuille-Rayleigh-Bénard flows, Proceedings $4^{\text {th }}$ ICCHMT, Paris-Cachan, 1 (2005) 266.

[45] A. Benzaoui, X. Nicolas, S. Xin, Num. Heat Trans. B, 48 (2005) 277.

[46] K. Goda, J. Comp. Phys., 30 (1979) 76.

[47] A. Benzaoui, Simulation numérique des écoulements de Poiseuille-Rayleigh-Bénard Application aux procédés de fabrication de couches minces par CVD, PhD thesis, Université de Marne la Vallée, 2006.

[48] F. C. Eversteyn, P. J. W. Severin, C. H. J. van den Brekel, H. L. Peek, J. Electrochem. Soc., 117 (1970) 925.

[49] W. K. S. Chiu, Y. Jaluria, J. Mater. Res., 15 (2000) 317.

[50] S. Xin, X. Nicolas, P. Le Quéré, Num. Heat Trans. A, 50 (2006) 467. 


\section{Figure captions}

Figure 1: Geometry and thermal boundary conditions (the vertical lateral walls are adiabatic).

Figure 2: Geometry and thermal boundary conditions of the 2D numerical test case used for the code validation corresponding to Eversteyn et al.'s experiments [48].

Figure 3: Deposition rates of silicon in the streamwise direction along the susceptor in the experiments of Eversteyn et al. [48] and in 2D numerical simulations (present and [37]).

Figure 4: Temperature field in the horizontal mid-plane, at $\mathrm{z}=0.5$, for $(\mathrm{a}, \mathrm{c}, \mathrm{e})$ no excited flows of 10 longitudinal rolls and (b, d, f) excited flows of 10 wavy rolls: (a, b) case 1 , (c, d) case 2 and (e, f) case 3 of table 2. Flow direction is from left to right.

Figure 5: Time average deposition rate of silicon $<\mathrm{G}>$ on the susceptor surface, for (a, c, e) the longitudinal roll flows and (b, d, f) the wavy roll flows of figure 4. (a, b) case 1, (c, d) case 2 and (e, f) case 3 of table 2.

Figure 6: Comparison of the transversal profiles of the average deposition rate of silicon $<\mathrm{G}>$ at different axial coordinates for the longitudinal and wavy roll flows of figures 4 and 5: (a) case $1,(\mathrm{~b})$ case 2 and (c) case 3 of table 2.

Figure 7: Influence of the Soret effect on the transversal profiles of the average deposition rate of silicon $<\mathrm{G}>$ at different axial coordinates, for (a) the longitudinal roll flow and (b) the wavy roll flow of case 3 of table $2(\mathrm{Re}=80, \mathrm{Ra}=10000)$. 


\section{Tables}

\begin{tabular}{ccc} 
mixture properties & $\mathrm{H}_{2} / \mathrm{SiH}_{4}$ & $\mathrm{~N}_{2} / \mathrm{SiH}_{4}$ \\
\hline$\rho^{\circ}\left(\mathrm{kg} / \mathrm{m}^{3}\right)$ & 0.0417 & 0.5705 \\
$\rho_{\mathrm{h}}\left(\mathrm{kg} / \mathrm{m}^{3}\right)$ & 0.0278 & 0.3803 \\
$\mathrm{M}(\mathrm{g} / \mathrm{mol})$ & 2.0545 & 28.085 \\
$\mathrm{C}_{\mathrm{p}}{ }^{\circ}(\mathrm{J} / \mathrm{kg} \mathrm{K})$ & 14306 & 1100.2 \\
$\nu^{\circ} \times 10^{6}\left(\mathrm{~m}^{2} / \mathrm{s}\right)$ & 339.3 & 49.39 \\
$\alpha^{\circ} \times 10^{6}\left(\mathrm{~m}^{2} / \mathrm{s}\right)$ & 495.5 & 70.63 \\
$\mathrm{D}^{\circ} \times 10^{6}\left(\mathrm{~m}^{2} / \mathrm{s}\right)$ & 193.2 & 57.70 \\
$\alpha_{\mathrm{T}}{ }^{\circ}$ & 0,715 & 0,06 \\
\hline
\end{tabular}

Table 1 : Physical properties of the $\mathrm{H}_{2} / \mathrm{SiH}_{4}$ and $\mathrm{N}_{2} / \mathrm{SiH}_{4}$ mixtures at $\mathrm{P}^{\circ}=101325 \mathrm{~Pa}, \mathrm{~T}^{\circ}=600$ $\mathrm{K}$ and $\Omega^{\circ}=2 \%$.

\begin{tabular}{ccccc} 
& & Case 1 & Case 2 & Case 3 \\
\hline geometric parameters & $\mathrm{A}$ & 200 & 100 & 100 \\
& $\mathrm{~A}_{\mathrm{e}}$ & 1 & 1 & 1 \\
& $\mathrm{~B}$ & 10 & 10 & 10 \\
& $H[\mathrm{~cm}]$ & 5.6 & 7.0 & 5.6 \\
\hline Mesh size & $\mathrm{N}_{\mathrm{x}} \times \mathrm{N}_{\mathrm{y}} \times \mathrm{N}_{\mathrm{z}}$ & $1000 \times 120 \times 30$ & $600 \times 150 \times 40$ & $600 \times 150 \times 40$ \\
\hline boundary conditions & $\mathrm{T}_{\mathrm{h}}[\mathrm{K}]$ & 900 & 900 & 900 \\
& $\mathrm{~T}_{\mathrm{c}}[\mathrm{K}]$ & 300 & 300 & 300 \\
& $\Omega_{0}$ & 0.02 & 0.02 & 0.02 \\
& $\mathrm{P}_{0}[\mathrm{~Pa}]$ & 101325 & 101325 & 101325 \\
\hline flow parameters & $\mathrm{Ra}$ & 10000 & 20000 & 10000 \\
& $\mathrm{Re}$ & 150 & 150 & 80 \\
& $\mathrm{Pr}$ & 0.68 & 0.68 & 0.68 \\
& $\mathrm{Sc}$ & 1.76 & 1.76 & 1.76 \\
& $U_{\text {mean }}[\mathrm{m} / \mathrm{s}]$ & 0.91 & 0.73 & 0.48 \\
& $\mathrm{Da}$ & 5.6 & 7.1 & 5.6 \\
\hline agitator parameters & $\mathrm{f}$ & 0.14 & 0.15 & 0.11 \\
& $\mathrm{~V}_{\mathrm{exc}}$ & 1.5 & 1.5 & 4 \\
\hline
\end{tabular}

Table 2 : Dimensionless and dimensional parameters defining the three simulated flow classes. 


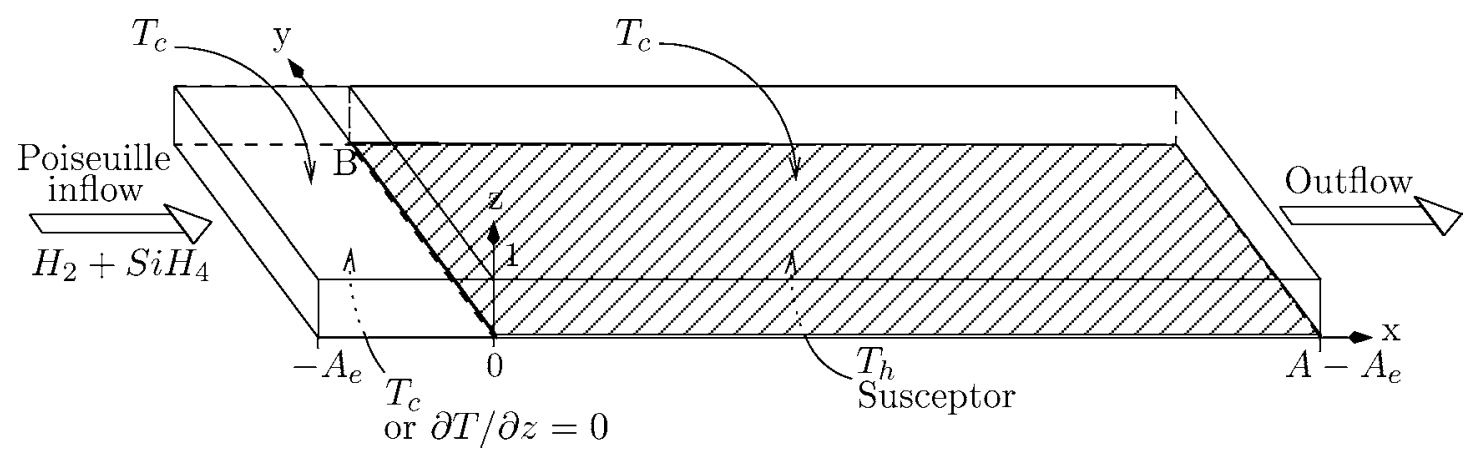

Figure 1: Geometry and thermal boundary conditions (the vertical lateral walls are adiabatic).

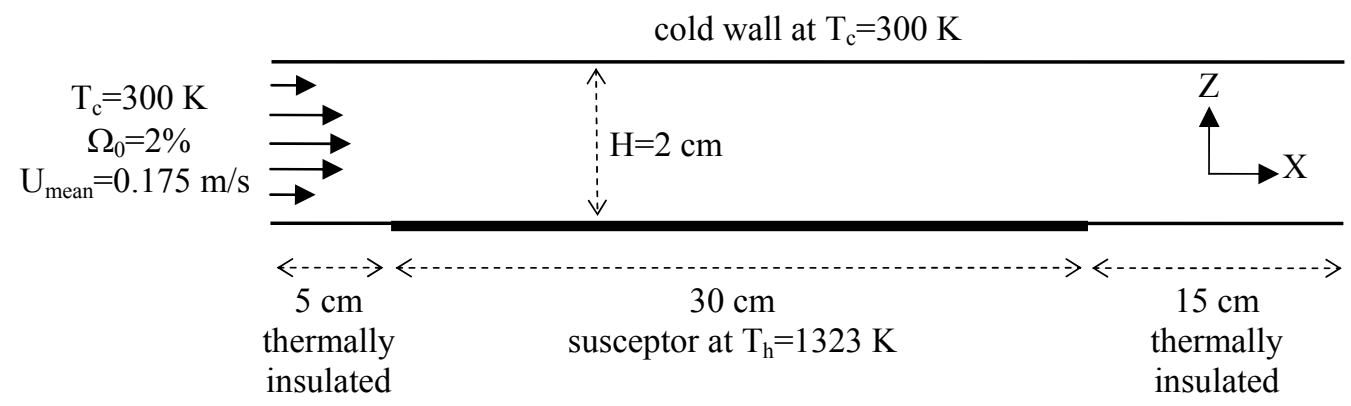

Figure 2: Geometry and thermal boundary conditions of the 2D numerical test case used for the code validation corresponding to Eversteyn et al.'s experiments [48].

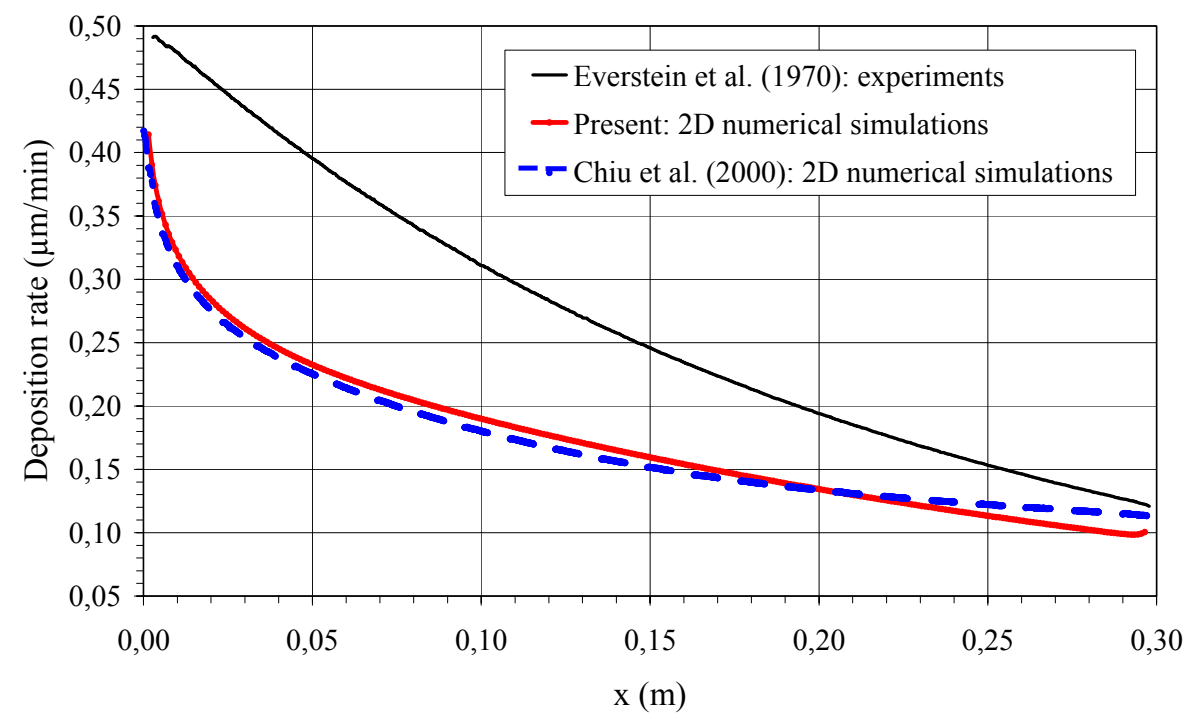

Figure 3: Deposition rates of silicon in the streamwise direction along the susceptor in the experiments of Eversteyn et al. [48] and in 2D numerical simulations (present and [37]). 
(a) 10

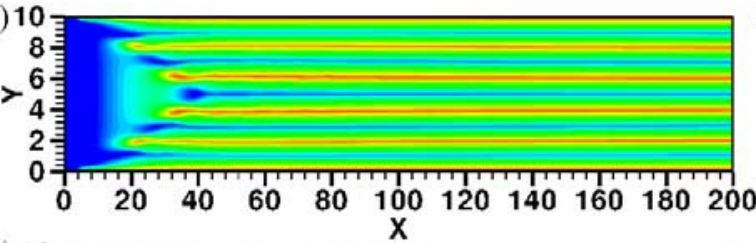

(c)

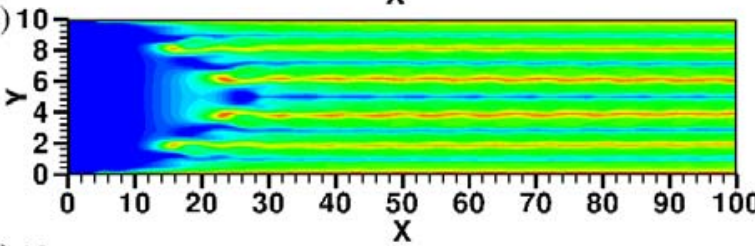

(e)

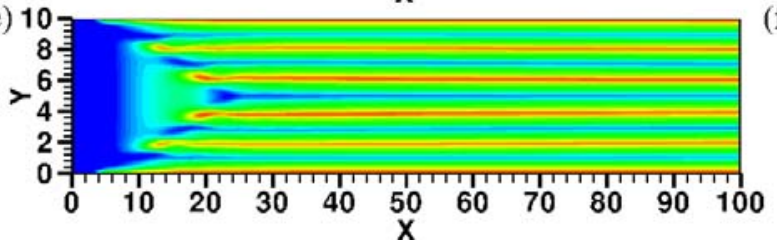

(b) 10

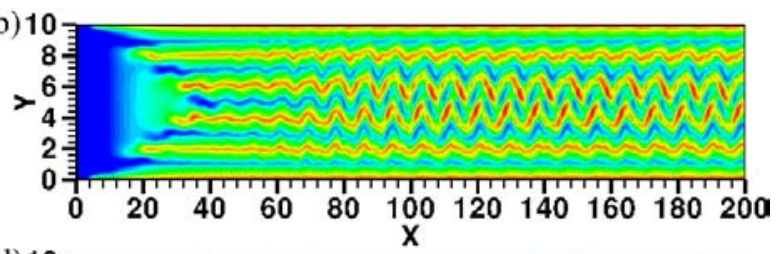

(d) 10
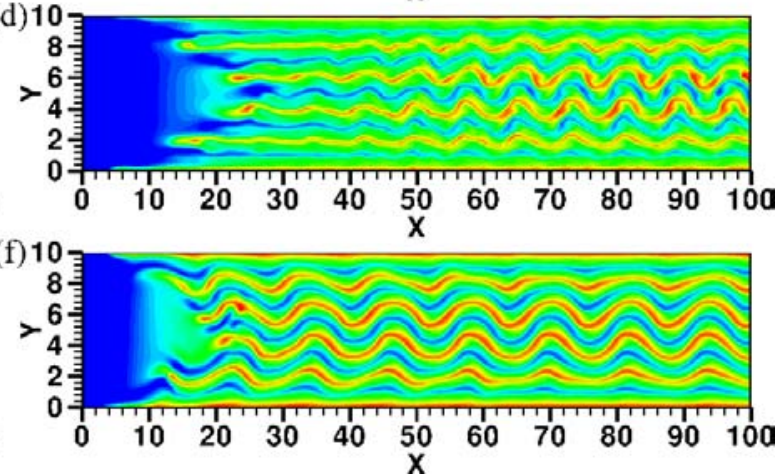

Figure 4: Temperature field in the horizontal mid-plane, at $\mathrm{z}=0.5$, for (a, c, e) no excited flows of 10 longitudinal rolls and (b, d, f) excited flows of 10 wavy rolls: (a, b) case 1, (c, d) case 2 and (e, f) case 3 of table 2. Flow direction is from left to right. 

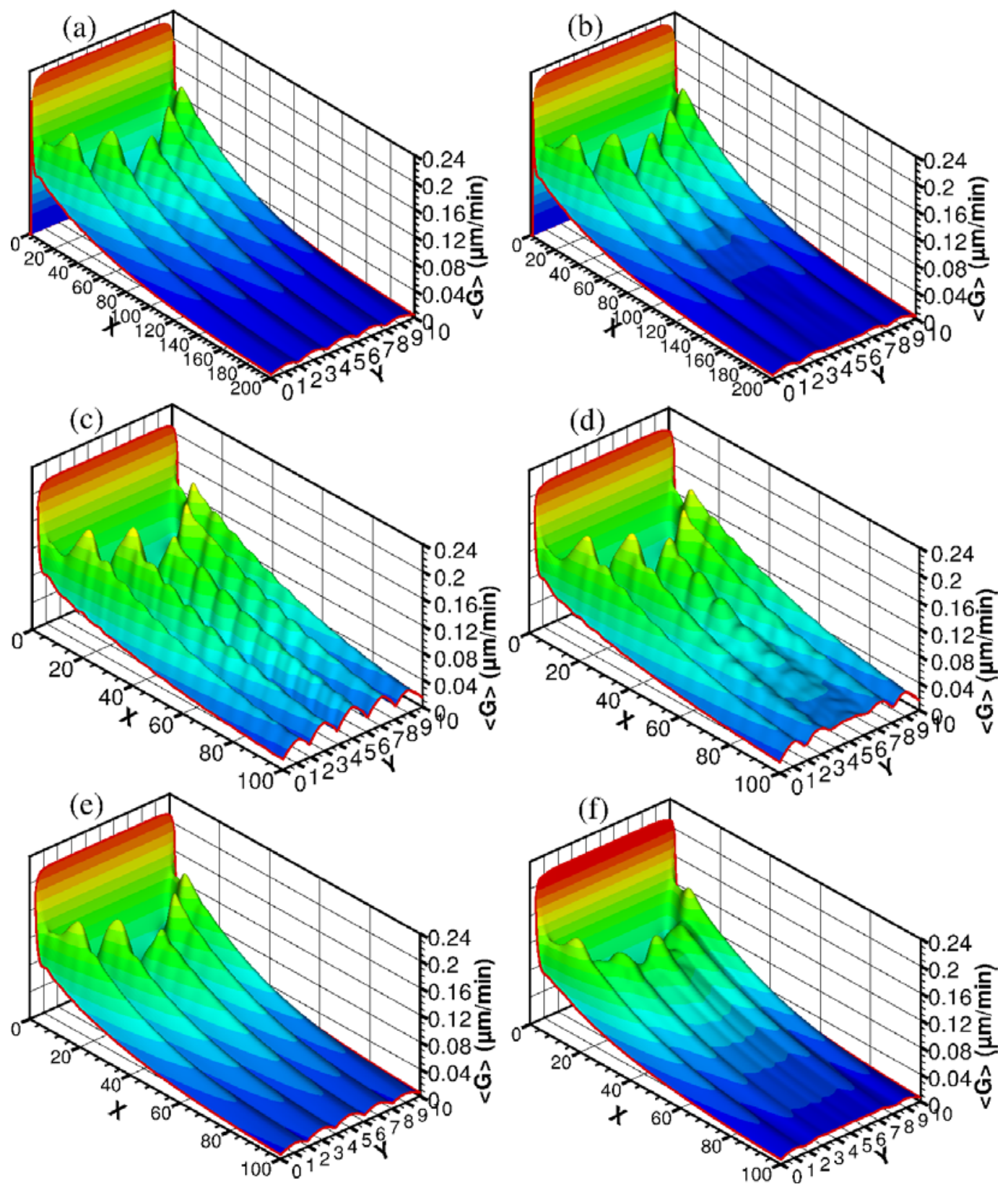

Figure 5: Time average deposition rate of silicon $<\mathrm{G}>$ on the susceptor surface, for (a, c, e) the longitudinal roll flows and (b, d, f) the wavy roll flows of figure 4. (a, b) case 1, (c, d) case 2 and $(e, f)$ case 3 of table 2. 

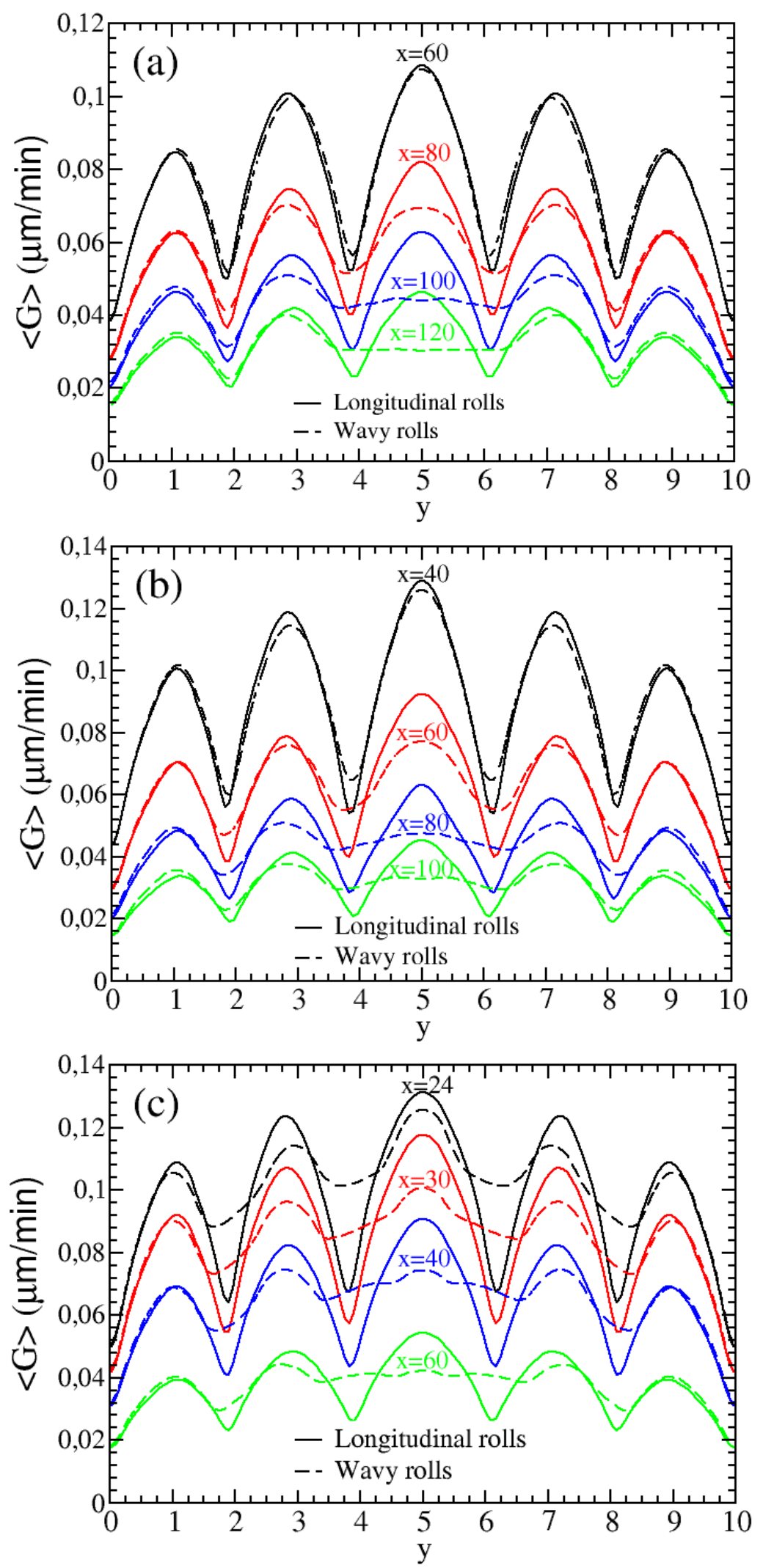

Figure 6: Comparison of the transversal profiles of the average deposition rate of silicon $<\mathrm{G}>$ at different axial coordinates for the longitudinal and wavy roll flows of figures 4 and 5: (a) case 1 , (b) case 2 and (c) case 3 of table 2 . 

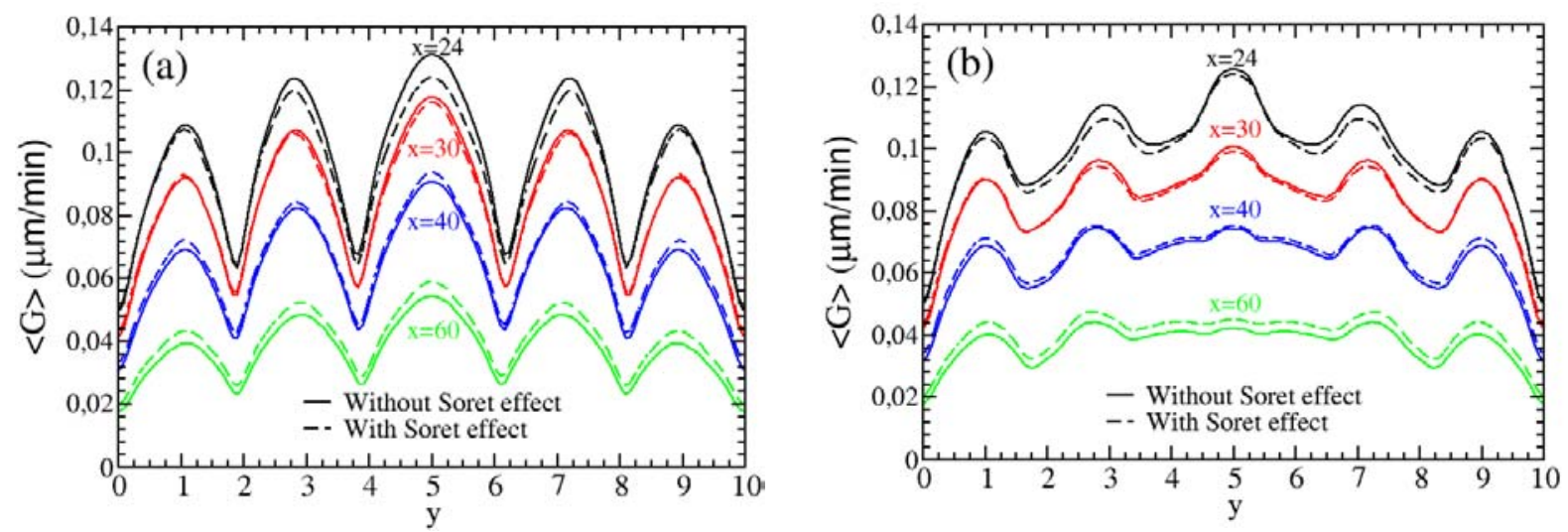

Figure 7: Influence of the Soret effect on the transversal profiles of the average deposition rate of silicon $<\mathrm{G}>$ at different axial coordinates, for (a) the longitudinal roll flow and (b) the wavy roll flow of case 3 of table $2(\mathrm{Re}=80, \mathrm{Ra}=10000)$. 